\title{
Improved rare earth elements recovery from fluorescent lamp wastes applying supported liquid membranes to the leaching solutions
}

\author{
S. Pavón ${ }^{1}$, A. Fortuny ${ }^{1}$, M.T. Coll ${ }^{2}$, A.M. Sastre ${ }^{3}$ \\ ${ }^{1}$ Chemical Engineering Department, EPSEVG, Universitat Politècnica de Catalunya, Vilanova $i$ la \\ Geltrú, Víctor Balaguer 1, 08800, Spain \\ ${ }^{2}$ Agri-Food Engineering and Biotechnology Department, ESAB, Universitat Politècnica de Catalunya, \\ Castelldefels, Esteve Terrades 8, 08860, Spain \\ ${ }^{3}$ Chemical Engineering Department, ETSEIB, Universitat Politècnica de Catalunya, Barcelona, \\ Diagonal 647, 08028, Spain
}

\begin{abstract}
Due to the continuously growing demand of rare earths in advanced technologies, end-of-life fluorescent lamps may become feasible rare earth elements (REEs) raw materials, reducing thus their supply risk. Considering acid leaching as the most common method in the metal recover from an endof-life product real scratch resulting from the fluorescent lamps, this paper proposes an improvement of the REEs recovery from these wastes adding a supported liquid membrane (SLM) step to minimize the loss of these metals in the first leaching (L1). $\mathrm{HNO}_{3}$ or $\mathrm{HCl}$ are the most appropriate acid agents in the L1 stage considering the balance between the Ca (II) impurity removal and the REEs losses minimization. These REEs lost can be entirely recovered from the L1 leachate by flat sheet supported liquid membranes (FSSLM) using Cyanex 923 as carrier and $\mathrm{Na}_{2}$ EDTA as the receiving phase. REEs, especially $\mathrm{Y}$ and $\mathrm{Eu}$, have been recovered in quantitative yields using a L1-FSSLM-L2 process.
\end{abstract}

\section{Keywords}

Fluorescent lamp wastes; Leaching; REEs recovery; REEs transport; Supported liquid membranes

\section{Introduction}

Nowadays, the recovery and separation of REEs has become one of the main interest subjects in the scientific community due their increasing consumption and supply risk. Moreover, the REEs growing consumption tendency does not seem to change in the upcoming years since their use is essential for the advanced technologies development. Neodymium, terbium, dysprosium, yttrium and europium have been considered as critical metals by several technical reports inducing the need for improved recovery pathways [1].

In order to provide a new way to recover and recycle REEs, the use of end-of-life products and the processing of their waste streams has turned into a promising alternative. According to the fact that the content of REEs in phosphors lamps can reach $27.9 \%$, though only $10 \%$ being recovered [2], these end-of-life products have been chosen as the source material of this research. Red phosphors $\mathrm{Y}_{2} \mathrm{O}_{3}: \mathrm{Eu}^{3+}(\mathrm{YOX})$, blue phosphors $\mathrm{BaMgAl}_{10} \mathrm{O}_{17}: \mathrm{Eu}^{2+}(\mathrm{BAM})$ and green phosphors $\mathrm{LaPO}_{4}: \mathrm{Ce}^{3+}, \mathrm{Tb}^{3+}$ (LAP), (Gd,Mg) $\mathrm{B}_{5} \mathrm{O}_{12}: \mathrm{Ce}^{3+}, \mathrm{Tb}^{3+}(\mathrm{CBT}),(\mathrm{Ce}, \mathrm{Tb}) \mathrm{MgAl}_{11} \mathrm{O}_{19}(\mathrm{CAT})$ are the three main phosphorus compounds of the fluorescent lamps [3].

Mechanical separation is the most established way to remove components such as plastics, glass and aluminium end caps. Afterwards, acid leaching is the most common method in the metal recover from an end-of-life product real scratch resulting from the fluorescent lamps [4,5]. Due to the REEs interest and the deficit between consumption and exploitation, taking advantage of these wastes seems to be promising. 
Up to now, although there are many investigations which focus on the characterization of real fluorescent lamp wastes and the recovery of REEs from these end-of-life products, industrial-scale applications are scare. A review regarding the yttrium recovery by leaching and SX from spent fluorescent lamps was published [6]. This review suggests a hydrometallurgical process to separate yttrium and calcium from acid leach liquor (leaching conditions $2 \mathrm{M}$ of sulfuric acid, $70^{\circ} \mathrm{C}, 15 \% \mathrm{w} / \mathrm{v}$ pulp density and $2 \mathrm{~h}$ of reaction time) using $20 \% \mathrm{v} / \mathrm{v}$ D2EHPA in kerosene by three-stage cross current extraction at the initial $\mathrm{pH}$ 0.02. Leaching using different solutions such as ammonium chloride, acetic acid, pure water, nitric and hydrochloric acid were investigated by Tunsu et al. for REEs and mercury recovery. Although hydrochloric and nitric acids are able to solubilizing most of the rare earths, the former at a concentration of $4 \mathrm{M}$ showed better efficiency for mercury [7]. Apart from the leaching studies, another important point is the choice of the extractant, because it must have a high selectivity to achieve the complete REEs separation. In this sense, literature studies depict a wide range of extractants, used to separate selectively the rare earths by the SX technique. Adding TBP into the Cyanex 272.Alamine $336 \mathrm{IL}$, a better $\mathrm{Nd} / \mathrm{Pr}$ separation factor was obtained [8]. The separation factors between $\mathrm{Ce}(\mathrm{IV}), \mathrm{Y}(\mathrm{III})$ and $\mathrm{Yb}(\mathrm{III})$ from aqueous nitrate solution were in the order: Cyanex 923/kerosene < TBP/kerosene < HQ (mixture of 8-hydroxyquinoline) +Cyanex 302/heptane [9]. Besides commercial extractants, ionic liquids have been also used in liquid-liquid extraction to recover and separate REEs. The Cyanex 272.Alamine $336 \mathrm{IL}$ was the best extractant to recover neodymium and praseodymium [10]. The $\mathrm{Nd}(\mathrm{III})$ separation is possible using Cyanex 272 and Cyanex 572 from a mixture with $\mathrm{Tb}(\mathrm{III})$ and $\mathrm{Dy}(\mathrm{III})$ in chloride media by SLM [11]. However, using the former, less metal is transported in the same working time. $99 \%$ of $\mathrm{Dy}(\mathrm{III})$ and $\mathrm{Nd}$ (III) transport from a $\mathrm{Dy} / \mathrm{Nd} / \mathrm{Fe}$ mixture in nitric acid medium using $\left[\mathrm{C}_{8} \mathrm{mim}\right]\left[\mathrm{Tf} \mathrm{f}_{2} \mathrm{~N}\right]$ containing $\mathrm{N}, \mathrm{N}$-dioctyldiglycolamic acid (DODGAA) was obtained by using SLMs [12].

For delineating a complete potential hydrometallurgical process of REEs recovery and separation from fluorescent lamp waste samples, the current investigation aims on the first part of the hydrometallurgical process. That is, on the REEs recovery improvement from a YOX phosphors waste real sample to achieve the highest amount of these metals so that they can be selectively separated applying the cross-flow solvent extraction process using IL's as extractants in chloride media depicted in the previous investigation [13].

In order to evaluate the leaching efficiency for the REEs recovery from the fluorescent lamp wastes, different acidic leaching agents such as aqua regia, acetic, gluconic, hydrochloric and nitric acids have been tested. Once a leach liquor has been obtained, selective separation techniques should be used to achieve the REEs recovery. Several studies suggest a one-step leaching to REEs recovery from the solid waste, however, the fluorescent lamp wastes contain mainly calcium as an impurity. If the chosen technique is the REEs precipitation using oxalic acid [14], calcium becomes an insurmountable problem. Consequently, as shown in Fig. 1, two leaching steps are proposed, using the former to remove the main impurities (calcium). Unfortunately, a small REE amount is also dragged in the liquid fraction. For this reason, SLM was chosen to minimize the REEs losses, because this technique is economically viable to separate the metals presents at low concentrations, as is shown in literature [11,14]. The solid obtained from the L1 stage will be undergone to a second leaching (L2) using high acid concentration to obtain a liquor rich in REEs which will be mixed with the permeate fraction coming from the SLM stage. 


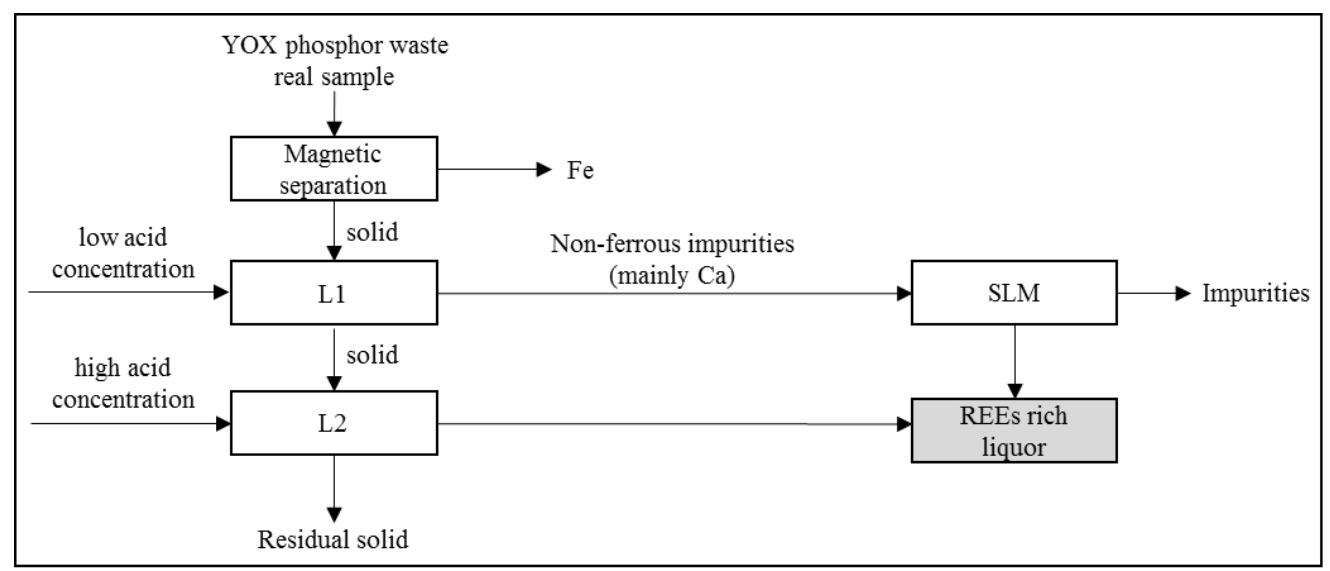

Fig. 1. Flow-sheet of the process to recover REEs from YOX fluorescent lamp wastes.

Our investigation is focused on the halophosphors rich in YOX phosphors because they have a high REEs content, especially yttrium and europium. The characterization and leaching of a fluorescent lamp waste in powder form for the REEs recovery has been carried out in the current study. Using a real waste sample induces to the evaluation of every process-step to achieve the complete REE recovery. The removal of the high impurity level is a demanding key step. In this sense, it is necessary to carry out a preliminary leaching (L1) to separate most of the base metals, but in this stage some REEs are also lost. The innovation provided by this investigation is the use of SLMs to recover the REEs from the liquor obtained after the first leaching (L1) which contains REEs at low concentrations. To evaluate the viability of the proposed procedure and to determine the optimal experimental conditions for the metal ion transport, the SLM experiments have carried out by using flat sheet supported liquid membrane (FSSLM) previously and foremost to be able to apply a hollow fibre renewal configuration.

\section{Material and methods}

\subsection{Reagents}

The end-of-life fluorescent lamp samples were obtained from Recyberica Ambiental. The acids used as leaching solutions were: gluconic acid (50\%, Ref. 8.22057, Merck), acetic acid (Ref. 131008, Panreac), nitric acid (69\%, Ref. 131037, PanReac AppliChem) and hydrochloric acid (37\%, Ref. 131020, PanReac AppliChem) diluted with pure water (MilliQ, Millipore, > $18 \mathrm{M} \Omega / \mathrm{cm}$ ).

Cyanex 572 (Cy572) and Cyanex 923 (Cy923) were used as carriers in the SLM experiments since the acidic and neutral carriers are the most used in the REEs recovery field. While Cy572 is a mixture of phosphinic and phosphonic acids, Cy923 is a mixture of four trialkylphosphine oxides, with general formula $R_{3} P(O), R_{2} R^{\prime} P(O), R^{\prime}{ }_{2} P(O)$ and $R^{\prime}{ }_{3} P(O)$, where $R^{\prime}$ refers to n-octyl and $R^{\prime}$ denotes n-hexyl groups $[16,17]$. Both Cyanex carriers were kindly supplied by Cytec Canada Industries and used as received. Detailed specifications of these extractants are summarized in Table 1. Kerosene from Sigma-Aldrich was used as a diluent (Ref. 607010). $\mathrm{HCl}$ and $\mathrm{Na}_{2}$ EDTA from PanReac AppliChem (Ref. 131669) were used as stripping agents.

Table 1. Physical properties of Cy572 and Cy923.

\begin{tabular}{ccccc}
\hline $\begin{array}{c}\text { Commercial } \\
\text { name }\end{array}$ & $\begin{array}{c}\text { Content } \\
\%\end{array}$ & $\begin{array}{c}\text { Density }\left(\mathbf{2 5}^{\circ} \mathbf{C}\right) \\
\mathbf{k g} \cdot \mathbf{m}^{-3}\end{array}$ & $\begin{array}{c}\text { Viscosity }\left(\mathbf{2 5}^{\circ} \mathbf{C}\right) \\
\mathbf{m P a} \cdot \mathbf{s}\end{array}$ & $\begin{array}{c}\text { Av. Mol. Weight } \\
\mathbf{g} \cdot \mathbf{m o l}^{-1}\end{array}$ \\
\hline Cy572 [18] & 100 & 933 & $<50$ & $310^{\text {a }}$ \\
Cy923 [19] & 93 & 880 & 40 & 348 \\
\hline
\end{tabular}

${ }^{a}$ Experimental data by potentiometric titration in water/ethanol 


\subsection{Characterization of the waste}

The end-of-life fluorescent lamps wastes supplied by Recyberica Ambiental was used as received, without crushing or grinding since the sample was already in the powder form.

SEM/EDX (INCA250, Oxford Instruments, Oxford, UK) and X-ray photoelectron spectroscopy (XPS) (SPECS, XR-50 Dual anode source, non-monochromated "Al k-alpha, Mg k-alpha") were applied to determine the solid sample composition. The analyses of the fluorescent lamp wastes using both techniques were measured in triplicate.

Aqua regia was used as reference to determine the maximum leachable amount of metals from the waste. The aqua regia was prepared by mixing concentrated hydrochloric and nitric acids at 3:1 v/v ratio. $10 \mathrm{~g}$ of waste were stirred with $0.1 \mathrm{~L}$ of aqua regia at $90 \pm 2^{\circ} \mathrm{C}$ for $2 \mathrm{~h}$. After regaining standard conditions, it was filtered (Filter Paper 1001 070, Whatman International Ltd) and the volume was adjusted to $0.1 \mathrm{~L}$ with pure water. The concentration of the metals in the aqueous samples was determined by atomic emission spectrometry using a 4100 MP AES System (Agilent Technologies) within the typical $95 \%$ confidence interval.

Molybdenum blue method was chosen as the standard determination method for phosphor, as reported elsewhere $[20,21]$. The concentration of this metal was colorimetrically determined using UVVIS spectroscopy (Agilent Technologies, Cary 60) at $660 \mathrm{~nm}$.

\subsection{Screening of leaching agents}

Pure water, gluconic acid $\left(\mathrm{HOCH}_{2}(\mathrm{CHOH})_{4} \mathrm{COOH}\right) 1 \mathrm{M}$, acetic acid $\left(\mathrm{CH}_{3} \mathrm{COOH}\right) 1 \mathrm{M}$, nitric and hydrochloric acid of various concentrations $(0.5 \mathrm{M}, 1 \mathrm{M}, 2 \mathrm{M})$ were investigated as leaching solutions. The experiments were carried out using $10 \mathrm{~g}$ of end-of-life fluorescent lamps and $0.1 \mathrm{~L}$ of leaching solutions $(10 \% \mathrm{w} / \mathrm{v})$, using magnetic stirring $(200 \pm 10 \mathrm{rpm})$ at different contact times and room temperature $\left(20 \pm 2{ }^{\circ} \mathrm{C}\right)$. The non-dissolved solids were oven-dried overnight at $100{ }^{\circ} \mathrm{C}$ (Selecta, Conterm Ref. 2000209). A second leaching (L2) was done using the dry non-dissolved solids from L1 with a higher acid concentration $(2 \mathrm{M})$ and the same $S: L$ ratio. The leaching experiments were done in triplicate.

\subsection{Supported liquid membranes procedure}

SLM is the most appropriate technique to recover the REEs from the L1 leachates since the concentration of these metals is low and therefore it permits the process intensification. In the flat sheet supported liquid membrane configuration, a microporous polymer film placed between the feed and receiving cells is impregnated with the carrier that selectively binds to a target metal ion. A microporous polytetrafluoroethylene support (Fluoropore ${ }^{\mathrm{TM}}$ FHLP04700, Merck Millipore), $4.7 \mathrm{~cm}$ diameter, $85 \%$ porosity, thickness $150 \mu \mathrm{m}, 0.45 \mu \mathrm{m}$ pore size and $11.4 \mathrm{~cm}^{2}$ of effective membrane area was used as the basic matrix. The transport experiments were carried out using the same experimental set-up and procedure depicted by Pavon et al. [11].

The L1 leachate is used as the feed solution, the carrier was prepared dissolving Cy572 or Cy923 in kerosene and $\mathrm{HCl} 1.2 \mathrm{M}$ or $\mathrm{Na}_{2}$ EDTA $0.05 \mathrm{M}$ were the stripping agents chosen respectively depending on the carrier used. The feed and the receiving solutions were magnetically stirred at $1000 \mathrm{rpm}$ at room temperature $\left(20 \pm 2^{\circ} \mathrm{C}\right)$. Samples from both solutions were taken every hour, until completed treatment time of $8 \mathrm{~h}$. The metal concentrations were quantified by atomic emission spectrometry.

The permeability coefficient of each metal was obtained from the Eq. (1) derived by combining metal balance in the feed cell and the Fick's law in the membrane [22-25]:

$$
\ln \frac{[M e]}{[M e]_{0}}=-P \cdot \frac{A}{V} \cdot t
$$


where $[\mathrm{Me}]$ and $[\mathrm{Me}]_{0}$ are the metal ion concentration $\left(\mathrm{g} \cdot \mathrm{L}^{-1}\right)$ in the feed cell at time (t) and initial time $\left(\mathrm{t}_{0}\right)$, respectively; $P$ is the permeability coefficient $\left(\mathrm{m} \cdot \mathrm{s}^{-1}\right), A$ is the membrane area $\left(\mathrm{m}^{2}\right) ; V$ is the volume of the feed solution in the cell $\left(\mathrm{m}^{3}\right)$ and $t$ is the time (s).

\section{Results and discussion}

\subsection{Waste characterization}

To characterize the fluorescent lamp wastes, the sample was dried at $60 \pm 1^{\circ} \mathrm{C}$ until constant weight, and $0.3 \%$ weight loss was observed. The sample complexity, consequence of the particle size and the variety of metals present, requires different analytical techniques for a complete characterization of the starting material.

In this sense, SEM/EDX analysis was chosen to elucidate the heterogeneity of the sample. As can be seen in Fig. 2, the sample is heterogeneous and the size of the particles differs over a wide range $(2.1-31.1 \mu \mathrm{m})$. Because of this, exhaustive spectra considering possible differences between small and large particles were done. Moreover, in the Fig. 2.b a contrast was applied to the same region shown in the Fig. 2.a and the results confirm that the bigger particles correspond to elements which are in glasses such as Al-Si and the smaller and more luminous ones are the REEs such a Y, Eu, La and Gd (Fig 2.c and Fig 2.d).
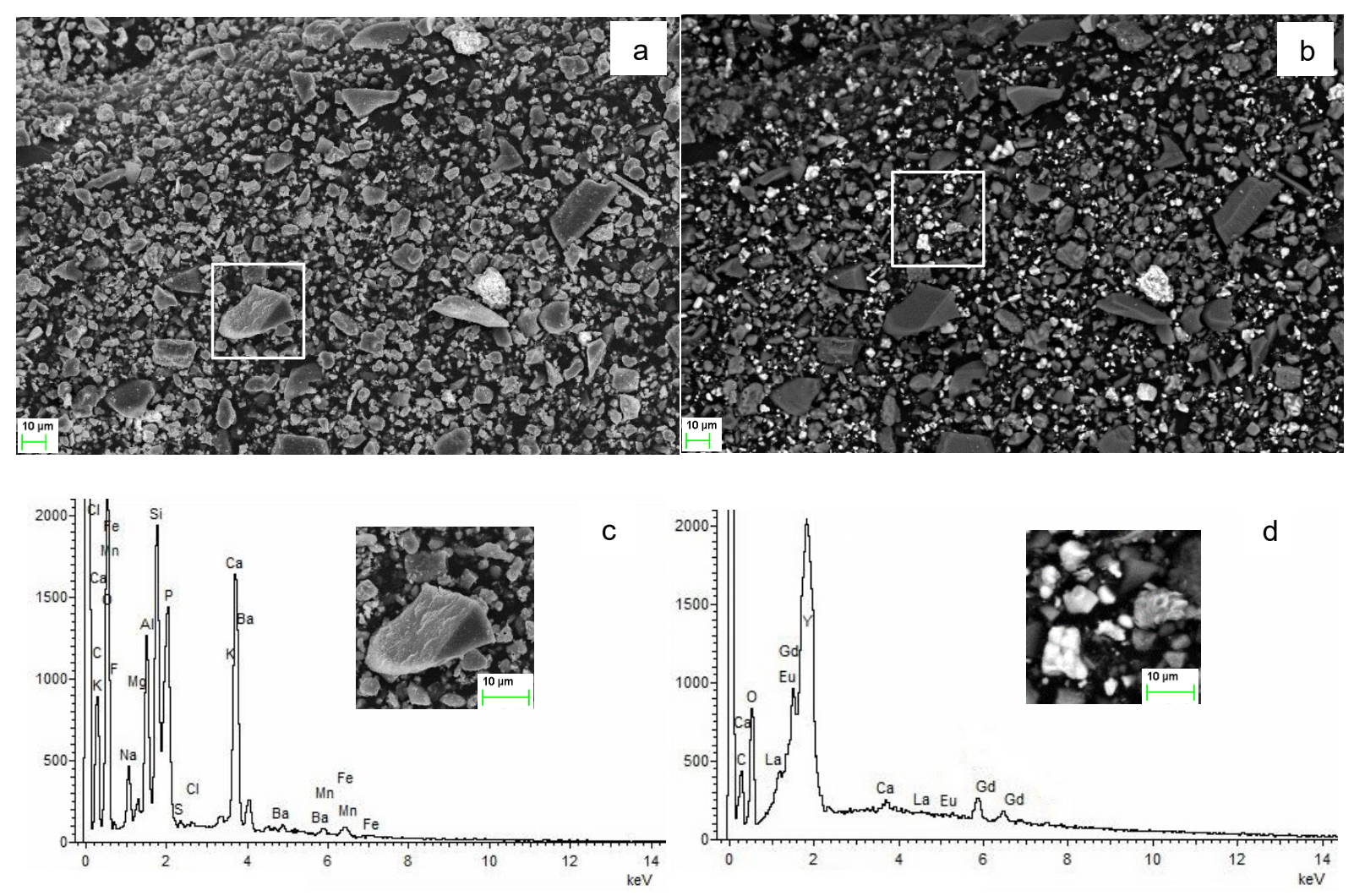

Fig. 2. SEM images of the fluorescent lamp wastes. a) $1.00 \mathrm{kX}$ magnification (Signal InLens). b) 1.00 kX magnification using light contrast applied (Signal QBSD). c) Magnification (2.00 kX) of the largest particles in the white-framed area shown in a). d) Magnification $(2.00 \mathrm{kX})$ of the smallest particles in the white-framed area shown in b).

For acquiring further information, XPS technique for screening the metals included in the sample was applied. The relative composition of the detected metals showed a high dispersion in function of the analysed sample point. The complex composition revealed by XPS showed the existence of several strategic metals present in the waste. Especially yttrium and europium achieved high content in the waste compared to other REEs (Fig. 2.d). Moreover, the total REEs relative percentage in the end-oflife fluorescent lamp wastes is $6.3 \pm 0.04 \%$ (Table 2 ). 
Table 2. Analysed elements and their content in the dried waste using XPS technique.

\begin{tabular}{clc}
\hline & Element & $\% \mathrm{w} / \mathrm{w}$ \\
\hline Non-REEs & $\mathrm{O}$ & $43.1 \pm 1.0$ \\
& $\mathrm{C}$ & $20.0 \pm 2.1$ \\
& $\mathrm{Al}$ & $12.3 \pm 0.9$ \\
& $\mathrm{Ca}$ & $5.8 \pm 0.1$ \\
& $\mathrm{Na}$ & $5.5 \pm 0.1$ \\
& $\mathrm{P}$ & $3.7 \pm 0.2$ \\
& $\mathrm{~F}$ & $2.6 \pm 0.4$ \\
& $\mathrm{Co}$ & $0.5 \pm 0.1$ \\
REEs & $\mathrm{Fe}$ & $0.3 \pm 0.2$ \\
& $\mathrm{Y}$ & $5.4 \pm 0.1$ \\
& $\mathrm{Eu}$ & $0.5 \pm 0.1$ \\
& $\mathrm{La}$ & $0.2 \pm 0.1$ \\
& $\mathrm{Gd}$ & $0.1 \pm 0.01$ \\
& $\mathrm{Dy}$ & $0.01 \pm 0.03$ \\
& $\mathrm{Ce}$ & $0.003 \pm 0.001$ \\
\hline Total REEs & & $6.3 \pm 0.04$ \\
\hline
\end{tabular}

The chemical treatment with aqua regia has been applied for acquiring a standard reference of the elements that can be leached from the real sample. After a partial separation of large impurities, such as glass and plastic, the concentration of 26 metals from the waste was analysed by atomic emission spectrometry (Table 3 ). Achieving a representative waste composition, the experiment was carried out 25 times.

Table 3. Average elements content in the waste. Aqua regia leaching $\left(90 \pm 2{ }^{\circ} \mathrm{C}, 2 \mathrm{~h}\right)$.

\begin{tabular}{llc}
\hline & Element & $\mathrm{g}_{\text {metal }} \cdot \mathrm{kg}_{\text {waste }}{ }^{-1}$ \\
\hline Non-REEs & $\mathrm{Ca}$ & $79.0 \pm 3$ \\
& $\mathrm{P}^{*}$ & $43.3 \pm 2$ \\
& $\mathrm{Al}$ & $11.0 \pm 0.1$ \\
& $\mathrm{Fe}$ & $5.0 \pm 0.01$ \\
& $\mathrm{Ba}$ & $4.0 \pm 0.2$ \\
& $\mathrm{Sr}$ & $4.0 \pm 0.1$ \\
& $\mathrm{Mn}$ & $2.0 \pm 0.1$ \\
& $\mathrm{Na}$ & $1.7 \pm 0.1$ \\
$\mathrm{Mg}$ & $1.5 \pm 0.01$ \\
& $\mathrm{~K}$ & $0.9 \pm 0.1$ \\
& $\mathrm{~B}$ & $0.7 \pm 0.1$ \\
& $\mathrm{Sb}$ & $0.4 \pm 0.1$ \\
& $\mathrm{Cu}$ & $0.1 \pm 0.1$ \\
& $\mathrm{Ni}$ & $0.1 \pm 0.1$ \\
$\mathrm{Si}$ & $0.1 \pm 0.01$ \\
REEs & $\mathrm{Co}$ & Not detected \\
& $\mathrm{Hg}$ & Not detected \\
& $\mathrm{Y}$ & $84.0 \pm 8$ \\
& $\mathrm{Eu}$ & $6.0 \pm 0.1$ \\
& $\mathrm{La}$ & $1.6 \pm 0.3$ \\
& $\mathrm{Gd}$ & $1.1 \pm 0.8$ \\
& $\mathrm{~Tb}$ & $0.2 \pm 0.1$
\end{tabular}




\begin{tabular}{|c|c|c|}
\hline & $\mathrm{Ce}$ & $0.1 \pm 0.1$ \\
\hline & Dy & $0.1 \pm 0.01$ \\
\hline & $\mathrm{Nd}$ & $0.1 \pm 0.01$ \\
\hline & $\mathrm{Er}$ & Not detected \\
\hline & $\mathrm{Yb}$ & Not detected \\
\hline Total REEs & & $93.2 \pm 1.2$ \\
\hline
\end{tabular}

The REEs content average was $93.2 \pm 1.2 \mathrm{~g}^{\cdot \mathrm{kg}^{-1}}$. Calcium and yttrium achieving the largest amounts with an average of $79.0 \pm 3$ and $84.0 \pm 8 \mathrm{~g}$ metal $\cdot \mathrm{kg}^{-1}$ waste, respectively. As expected, $Y$ and Eu are the main REEs present in this waste because they are the relevant REEs of red phosphors $\left(\mathrm{Y}_{2} \mathrm{O}_{3}: \mathrm{Eu}^{3+}\right)$ [7].

Due to the similar amounts of $\mathrm{Ca}$ and $\mathrm{Y}$ the removal of the former is essential for a selective leaching to recover and separate the REEs. For this reason, a screening of different leaching agents has been carried out.

\subsection{Screening of leaching agents}

To evaluate the fluorescent lamp wastes leaching efficiency for the REEs recovery, different acidic leaching agents such as gluconic, acetic, hydrochloric and nitric acids have been compared. The studied parameters were acid concentration, contact time and different kind of acid.

\subsubsection{Leaching 1 (L1)}

Different kind of acids have been used to recover REEs from end-of-life products $[7,26,27]$. The most promising are the strong acids such as sulphuric, nitric and hydrochloric acid due to their strong acidic character [28,29]. However, considering the L1 leaching stage aim of maximizing the Ca (II) elimination rate and losing the minimum amount of REEs, sulphuric acid was discarded. To avoid the $\mathrm{Ca}_{2} \mathrm{SO}_{4}$ precipitation, other weak acids were chosen and evaluated by their efficiency to achieve the designed purpose. Hence, the L1 leaching experiments were carried out using pure water, acetic acid $1 \mathrm{M}$, gluconic acid $1 \mathrm{M}$, hydrochloric and nitric acid $1 \mathrm{M}$ as the leaching agents using a contact time of 10 min. As is shown in Fig. 3.a, the efficacy in removing Ca was: pure water < acetic acid (pKa 4.76) < gluconic acid (pKa 3.60) < nitric acid < hydrochloric acid linked to their increased acidic character. Hydrochloric and nitric acid were the optimal leaching agents because the removed Ca was 100 and $87 \%$, respectively. However, in order to minimize the REEs losses in this leaching step, $\mathrm{HCl} 1 \mathrm{M}$ seems to be the best choice (Fig. 3.a).

The $\mathrm{HCl}$ and $\mathrm{HNO}_{3}$ concentration and the contact time for both leaching agents were the main parameters studied. As can be seen in Fig. 3.b and Fig. 3.c, the difference of Ca eliminated using $1 \mathrm{M}$ or $2 \mathrm{M} \mathrm{HCl}$ and $\mathrm{HNO}_{3}$, was not significant because in all cases, the Ca removed was higher than $87 \%$. However, when $0.5 \mathrm{M}$ was used, Ca leaching dropped to approximately $60 \%$ in contrast to $1 \mathrm{M}$ or $2 \mathrm{M}$. REEs removal was higher using $2 \mathrm{M}$ of $\mathrm{HCl}$ or $\mathrm{HNO}_{3}$ than $1 \mathrm{M}$ of these leaching agents. The contact time experiments were carried out using a range from 5 to $15 \mathrm{~min}$. Despite of using $15 \mathrm{~min}$, higher amount of $\mathrm{Ca}$ is leached, $10 \mathrm{~min}$ is the optimal contact time condition to minimize the losses of REEs trying to maximize the $\mathrm{Ca}$ elimination. 

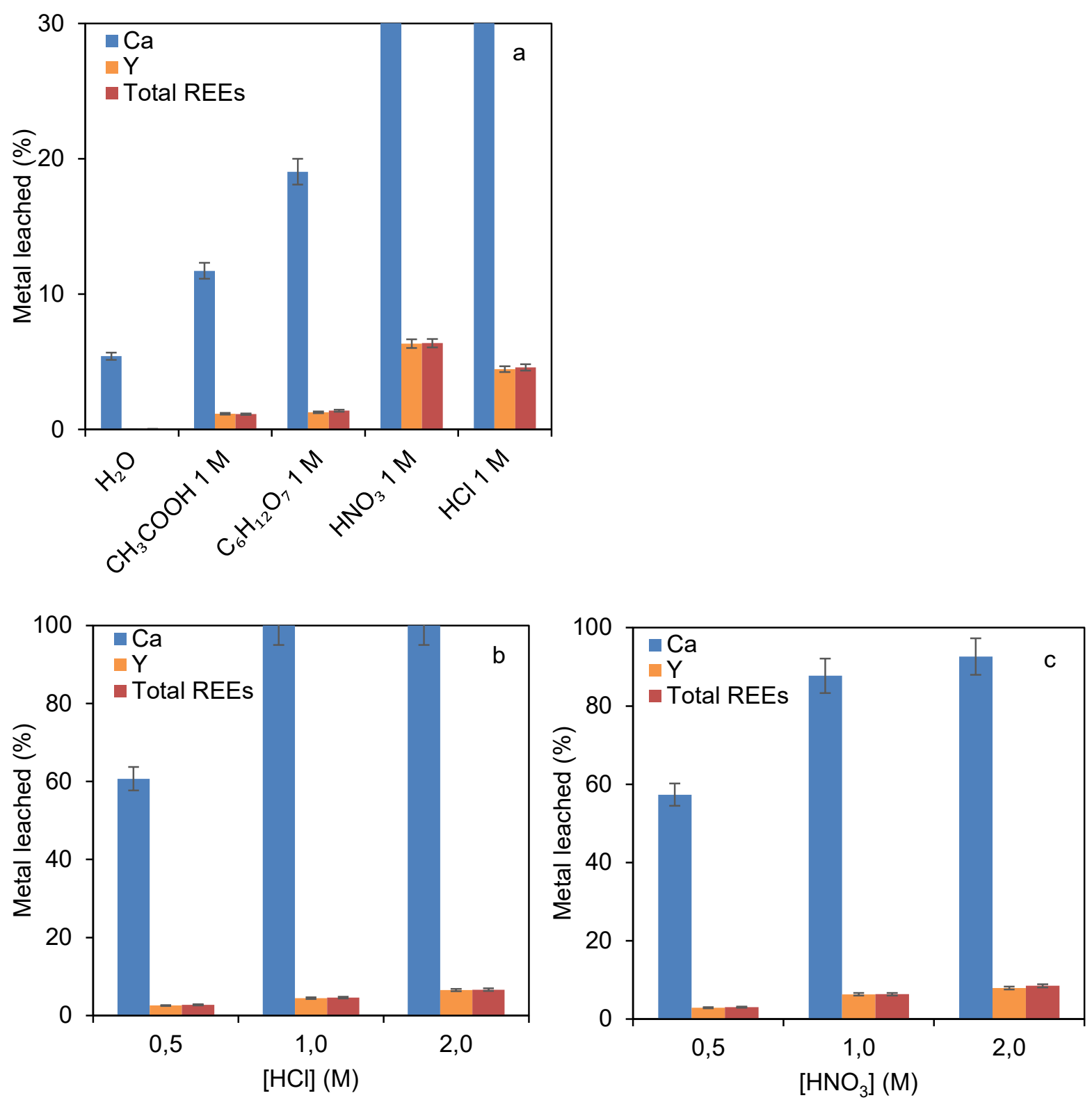

Fig. 3. $\mathrm{Ca}, \mathrm{Y}$ and total REEs leached (\%). S:L ratio of $10 \% \mathrm{w} / \mathrm{v}$, magnetic stirring $-200 \mathrm{rpm}$. a) Effect of different leaching agents at $1 \mathrm{M}$ : pure water, acetic acid, gluconic acid, hydrochloric acid and nitric acid. Contact time: 10 min. b) Effect of hydrochloric acid concentration. Contact time: 10 min. c) Effect of nitric acid concentration. Contact time: $10 \mathrm{~min}$.

In conclusion, the optimal conditions for the L1 step to minimize the REEs losses and maximize the Ca separation from the fluorescent lamp wastes are: $1 \mathrm{M}$ of $\mathrm{HCl}$ or $\mathrm{HNO}_{3}$ and a contact time of 10 min.

\subsubsection{Leaching 2 (L2)}

According to Tunsu et al., to recover completely REEs from fluorescent lamp wastes, acid agents with higher acidic character and severe working conditions are required [7]. Thus, $\mathrm{HCl}$ and $\mathrm{HNO}_{3}$ instead of weak acids were the chosen leaching agents to investigate the REEs recovery in the L2 leaching stage. The contact time was the studied parameter, maintaining the hydrochloric and nitric acid concentration at a constant level of $2 \mathrm{M}$. The metal leached percentages have been referred to the metal concentrations obtained using aqua regia. The leaching behaviours are presented in Fig 4. For $\mathrm{Eu}$ and $\mathrm{Y}$, the leached metal was stabilized after $48 \mathrm{~h}$. However, the $\mathrm{Gd}$ and La were not stabilized in whole the investigated time (168 h). Moreover, the metal leaching yield was above $80 \%$ for Eu using 
$\mathrm{HCl}$ or $\mathrm{HNO}_{3}$. These results are similar to the ones reported by Tunsu et al. [7] except for the La, since the percentage of metal leached is around $25 \%$ in contrast to only $5 \%$ in our investigation.
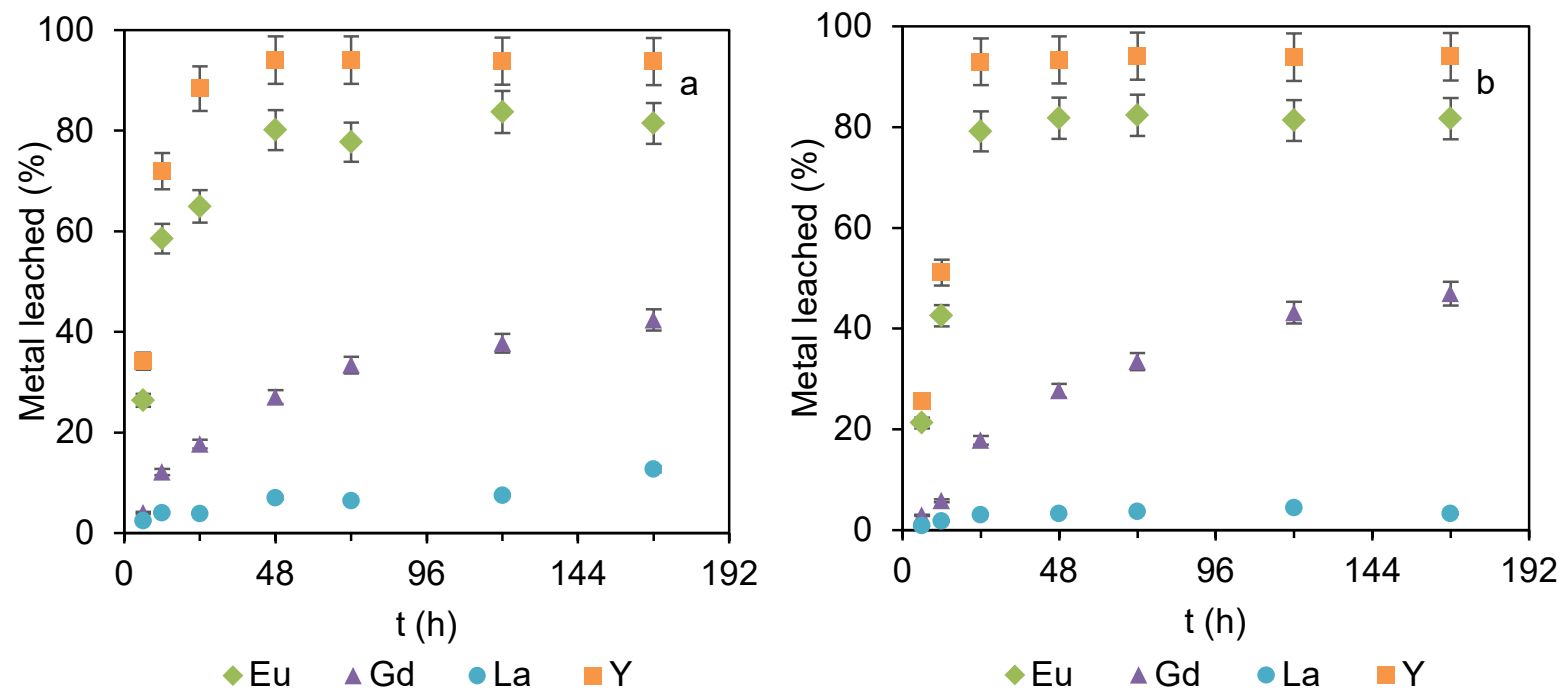

Fig. 4. Eu, Gd, La and Y leached (\%) over $168 \mathrm{~h}, \mathrm{~S}: \mathrm{L}$ ratio of $10 \% \mathrm{w} / \mathrm{v}$, magnetic stirring - $200 \mathrm{rpm}$. a) $\mathrm{HCl} 2 \mathrm{M}$. b) $\mathrm{HNO}_{3} 2 \mathrm{M}$.

In order to recover $\mathrm{Y}$ and Eu quantitatively from $\mathrm{L} 1$ solid waste, $\mathrm{HCl}$ and $\mathrm{HNO}_{3} 2 \mathrm{M}$ need to be applied for $48 \mathrm{~h}$. The recovery of $\mathrm{Gd}$ and La could be acquired at higher extensions using more drastic conditions in a 3rd leaching (L3).

\subsection{Supported liquid membranes}

Cy923 and Cy572 have been chosen to study the recovering of the REEs present in the L1 leachate by SLMs. Since the obtained results in the $\mathrm{L} 1$ using $\mathrm{HCl}$ and $\mathrm{HNO}_{3}$ were similar, both extractants can be used in the membranes experiments depending on the species, cationic or neutral, present in the media. When nitric acid was used as the leaching agent, the formed species are mainly neutral, whereas cationic species are produced by using hydrochloric acid. Since Cy923 extracts neutral species and Cy572 cationic ones, nitric acid was used as the media to leach REEs when the former extractant was utilized as the carrier, whereas hydrochloric acid was chosen for Cy572, as previous studies recommend $[30,31]$.

Considering that the complete Eu and $\mathrm{Y}$ recovery was achieved by solvent extraction at $\mathrm{pH}=1.5$ using Cy572 [13], the leachate $\mathrm{pH}$ was set to this value and used as a feed in an SLM experiment following the procedure depicted in section 2.4. Unfortunately, at these conditions, a precipitate appeared. This fact can be explained using the MEDUSA software since $\operatorname{REEPO}_{4}(\mathrm{~s})\left(\mathrm{YPO}_{4}(\mathrm{~s})\right.$ or $\left.\operatorname{EuPO}_{4}(\mathrm{~s})\right)$ is obtained above a pH value of 0.5 (Fig. 5).
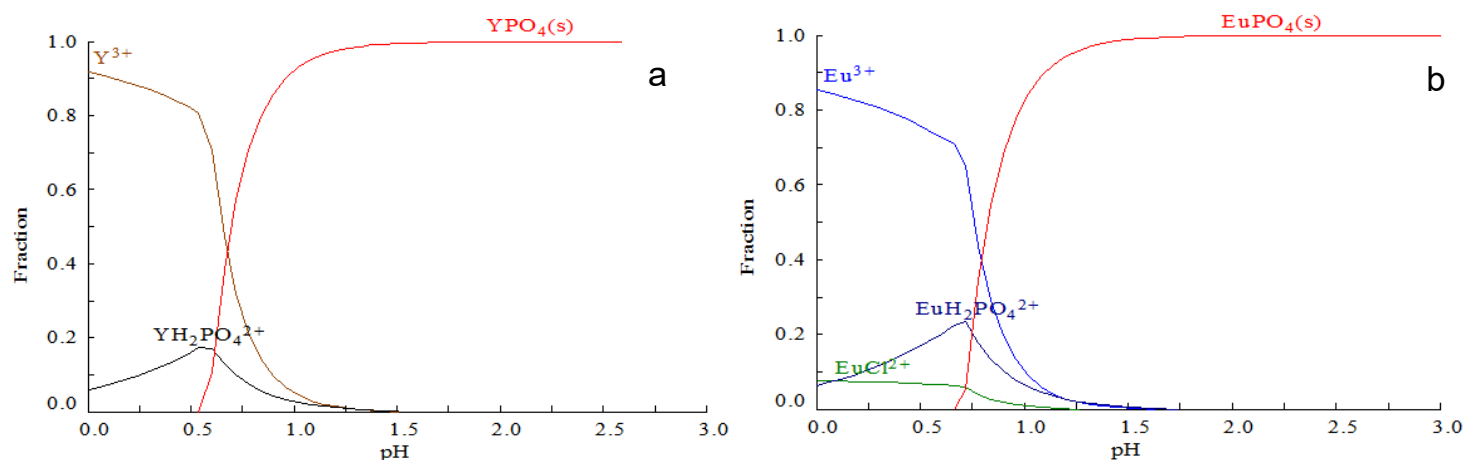

Fig. 5. Speciation diagram using MEDUSA software [32]. $\left[\mathrm{PO}_{4}{ }^{3-}\right]=0.2 \mathrm{M},\left[\mathrm{Ca}^{2+}\right]=0.2 \mathrm{M},[\mathrm{Cl}]=1 \mathrm{M}$, lonic strength: $1 \mathrm{M}$. a) Y $6 \cdot 10^{-3} \mathrm{M} \mathrm{b}$ ) Eu $3.3 \cdot 10^{-4} \mathrm{M}$. 
To avoid the precipitation in the feed solution, the $\mathrm{pH}$ was fit to 1.2. However, at this $\mathrm{pH}$ there had no metal transport using Cy572 $0.3 \mathrm{M}$ as carrier. Cause of the tight $\mathrm{pH}$ range to have REEs transport and avoid the REEPO ${ }_{4}(\mathrm{~s})$ precipitation, it seemed to be promising to change the strategy and use the Cy923 since using this extractant no $\mathrm{pH}$ conditioning is required to extract the REEs.

The SLM experiments using Cy923 were carried out using the leachate obtained from the L1 using 1 $\mathrm{M}$ of $\mathrm{HNO}_{3}$ for $10 \mathrm{~min}$. The composition of this leachate is depicted in Table 4. The $\mathrm{pH}$ of the feed solution was adjusted to 1.2 and four different concentrations of Cy923, 0.3, 0.6, 0.9 and $1.2 \mathrm{M}$, were investigated. Even though the use of strong acids to recover the REEs loaded has been reported in different investigations [17,33-35], one of the most common stripping agents, $\mathrm{HNO}_{3}$, was rejected since the same neutral complex species $\left.\left(\mathrm{Y}_{(} \mathrm{NO}_{3}\right)_{3}\right)$ would be formed in the receiving phase transporting it to the feed phase, thus, reducing the REEs transport through the membrane from the feed to the receiving phase. Hence, the $\mathrm{Na}_{2}$ EDTA $0.05 \mathrm{M}$ was chosen as the receiving solution in the membrane experiments to avoid the neutral complex species formation encouraging the anionic species ones.

Table 4. Composition of feed in FSSLM experiments. $\mathrm{HNO}_{3} 1 \mathrm{M}$ leaching and contact time of 10 min.

\begin{tabular}{llc}
\hline & Element & $\mathrm{mg} \cdot \mathrm{L}^{-1}$ \\
\hline Non-REEs & $\mathrm{Ca}$ & $6820 \pm 150$ \\
& $\mathrm{P}^{*}$ & $759 \pm 14$ \\
& $\mathrm{Fe}$ & $41 \pm 8.5$ \\
& $\mathrm{Ba}$ & $311 \pm 0.1$ \\
& $\mathrm{Sr}$ & $236 \pm 5.6$ \\
& $\mathrm{Mn}$ & $152 \pm 3.5$ \\
& $\mathrm{Si}$ & $132 \pm 3.1$ \\
& $\mathrm{Al}$ & $116 \pm 2.5$ \\
& $\mathrm{Na}$ & $90 \pm 2.1$ \\
& $\mathrm{Mg}$ & $64 \pm 1.7$ \\
& $\mathrm{~K}$ & $56 \pm 1.4$ \\
& $\mathrm{Sb}$ & $20 \pm 0.6$ \\
REEs & $\mathrm{Y}$ & $491 \pm 12$ \\
& $\mathrm{Eu}$ & $41 \pm 0.9$ \\
& $\mathrm{La}$ & $16 \pm 0.3$ \\
\hline Total REEs & \multicolumn{2}{c}{$548 \pm 6.6$} \\
\hline${ }^{*}$ Molybdenum blue method
\end{tabular}

Fig. 6 shows that the transported REEs increased with the carrier concentration. Meanwhile the $\mathrm{Ca}$, the most representative impurity of the sample, was not transported in any conditions. After 8 hours, the percentage of $Y$ transported was $40 \%$, using the highest Cy923 concentration. The Eu behaviour followed the same tendency that $Y$. However, the transport of $Y$ using $0.9 \mathrm{M}$ is similar to $1.2 \mathrm{M}$ of Cy923. Comparing the metal appeared in the receiving solution with the metals disappeared from the feed phase we can affirm that the loaded metals were wholly stripped. 

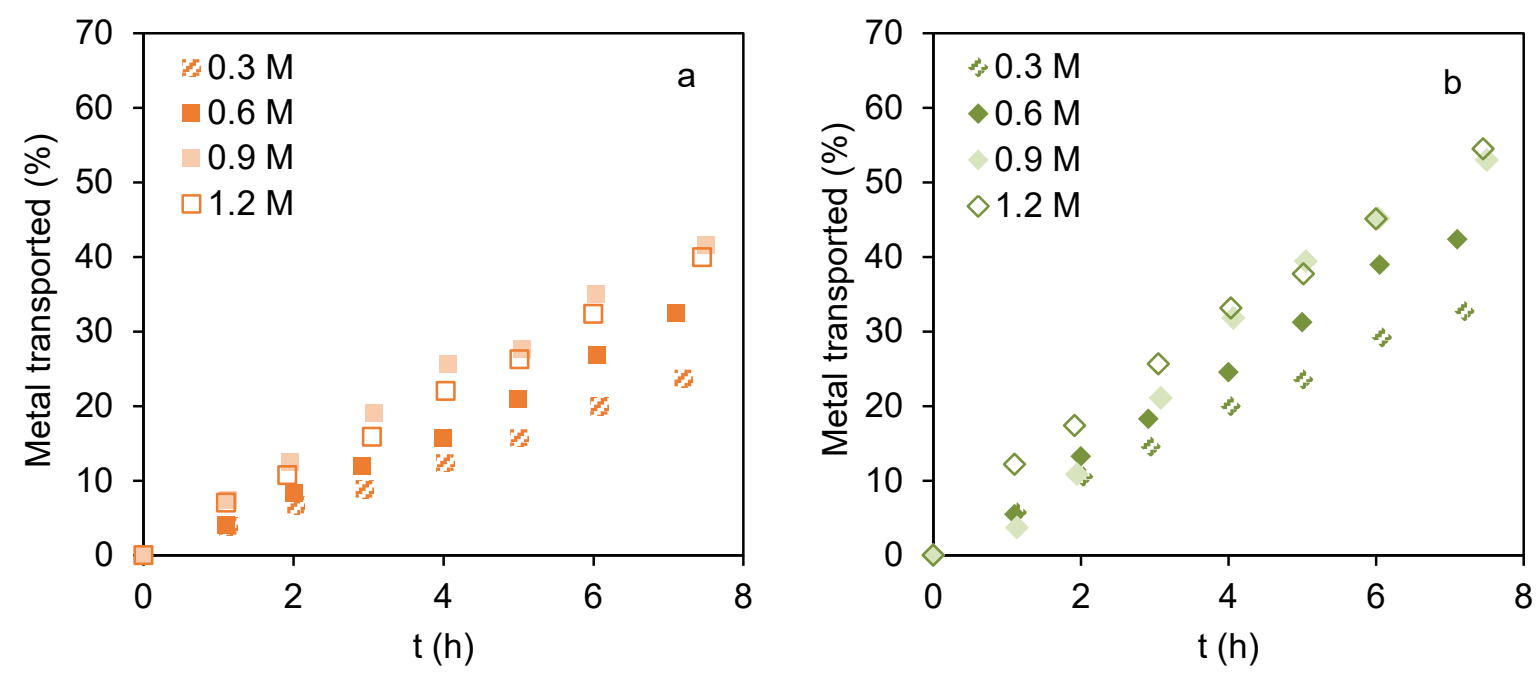

Fig. 6. Effect of Cy923 concentration on the REEs transport. Feed $\mathrm{pH}=1.2$. $\left[\mathrm{NO}_{3}{ }^{-}\right]=1 \mathrm{M}$. Receiving solution: $0.05 \mathrm{M} \mathrm{Na}_{2}$ EDTA. a) Y. b) Eu.

From the data, where the higher impurity in Ca form is removed, it is demonstrated that in order to avoid the REEs losses after the first leaching process, to use Cy923 as carrier is a viable option.

As shown in Fig. 7, the permeability increases when the carrier concentration increases until $0.9 \mathrm{M}$ of the carrier. This means that at low concentrations of Cy923 the metal transport is only controlled by the diffusion through the membrane, but at higher Cy923 concentrations, the effect of the shear stress become predominant, reducing the apparent permeability due to the increase in the viscosity.

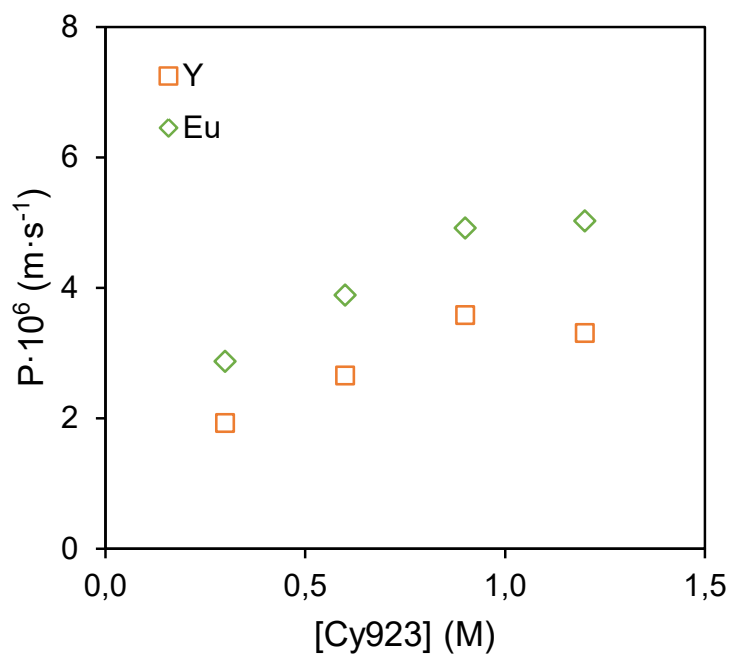

Fig. 7. Effect of the Cy923 concentration on the permeability of $Y$ and Eu.

The permeability coefficients using $0.9 \mathrm{M}$ of Cy923 for Eu and $\mathrm{Y}$ were $4.9 \cdot 10^{-6}$ and $3.6 \cdot 10^{-6} \mathrm{~m} \cdot \mathrm{s}^{-1}$, respectively. The results indicate that the Cy923-metal complex transport increases linearly when the carrier concentration range is $0.3-0.9 \mathrm{M}$. The permeation coefficients values are similar to those obtained for $\mathrm{Cd}(\mathrm{II})$ transport through hollow fibre supported strip dispersion (HFSD) by N.S. Rathore et al. using Cyanex 923 [36] and for Nd, Tb and Dy using Cyanex 572 and Cyanex 272 in the S. Pavon et al. [11].

To sum up, considering the scale-up industrial process using hollow fibre membrane modules, $7 \mathrm{~h}$ will be required to recover the $95 \%$ of REEs from $1 \mathrm{~m}^{3}$ of $\mathrm{L} 1$ leachate of $100 \mathrm{~kg}$ of the fluorescent lamp 
waste using a $33 \mathrm{~m}^{2}$ membrane area if a permeability coefficient is $3.6 \cdot 10^{-6} \mathrm{~m} \cdot \mathrm{s}^{-1}$ being this value for the $Y$ since it is the main REE in the fluorescent lamp waste.

\section{Conclusions}

YOX phosphors from end-of-life fluorescent lamps were investigated to evaluate their recycling potential. The main impurities of the real scratch were iron and calcium that were removed using magnetic separation and an acidic leaching stage respectively.

Nitric acid is the most appropriate leaching agent when Cy923 is used as the carrier in the SLM to recover the REEs because their recovery is obtained using a feed $\mathrm{pH}=1.2$. The losses of these metals in the first leaching stage have been minimized adding a membrane stage with a flat sheet configuration. Although Cy923 is able to recover these REEs losses, the higher permeability coefficients are obtained when the concentration of Cy923 is $0.9 \mathrm{M}$. Metals transport increases when the Cy923 concentration also increases, resulting in a reduction of the membrane area or the working time needed to achieve the REEs recuperation. Finally, an $\mathrm{L} 2$ stage using $\mathrm{HNO}_{3}$ or $\mathrm{HCl} 2 \mathrm{M}$ for $48 \mathrm{~h}$ is required to recover completely the REEs, especially $Y$ and Eu from the waste.

Based on the obtained results, the REEs can be completely recovered from their leachates optimizing the leaching process and using flat sheet supported liquid membranes.

\section{Acknowledgments}

This research was supported by the MINECO with its [grant number CTM2017-83581-R]. We express our gratitude to Recyberica Ambiental and Cytec Industries Inc. for providing free samples of the fluorescent lamp wastes, Cyanex 572 and Cyanex 923, respectively.

\section{References}

[1] U.S. Department of Energy, U.S. Department of Energy: Critical materials strategy, 2012. DOE/PI-0009.

[2] N.M. Ippolito, V. Innocenzi, I. De Michelis, F. Medici, F. Vegliò, Rare earth elements recovery from fluorescent lamps: A new thermal pretreatment to improve the efficiency of the hydrometallurgical process, J. Clean. Prod. 153 (2017) 287-298. doi:10.1016/j.jclepro.2017.03.195.

[3] X. Song, M.-H. Chang, M. Pecht, Rare-Earth Elements in Lighting and Optical Applications and Their Recycling, JOM. 65 (2013) 1276-1282. doi:10.1007/s11837-013-0737-6.

[4] F. Yang, F. Kubota, Y. Baba, N. Kamiya, M. Goto, Selective extraction and recovery of rare earth metals from phosphor powders in waste fluorescent lamps using an ionic liquid system, J. Hazard. Mater. 254-255 (2013) 79-88. doi:10.1016/J.JHAZMAT.2013.03.026.

[5] H. Liu, S. Zhang, D. Pan, J. Tian, M. Yang, M. Wu, A.A. Volinsky, Rare earth elements recycling from waste phosphor by dual hydrochloric acid dissolution, J. Hazard. Mater. 272 (2014) 96-101. doi:10.1016/J.JHAZMAT.2014.02.043.

[6] V. Innocenzi, I. De Michelis, F. Ferella, F. Vegliò, Secondary yttrium from spent fluorescent lamps: Recovery by leaching and solvent extraction, Int. J. Miner. Process. 168 (2017) 87-94. doi:10.1016/j.minpro.2017.09.017.

[7] C. Tunsu, C. Ekberg, T. Retegan, Characterization and leaching of real fluorescent lamp waste for the recovery of rare earth metals and mercury, Hydrometallurgy. 144-145 (2014) 91-98. doi:10.1016/j.hydromet.2014.01.019.

[8] Y. Liu, H.S. Jeon, M.S. Lee, Solvent extraction of Pr and Nd from chloride solutions using ternary extractant system of Cyanex 272, Alamine 336 and TBP, J. Ind. Eng. Chem. 31 (2015) 74-79. doi:10.1016/j.jiec.2015.06.009.

[9] M.I. Aly, B.A. Masry, M.S. Gasser, N.A. Khalifa, J.A. Daoud, Extraction of Ce (IV), Yb (III) and $Y(I I I)$ and recovery of some rare earth elements from Egyptian monazite using CYANEX 923 in kerosene, Int. J. Miner. Process. 153 (2016) 71-79. doi:10.1016/j.minpro.2016.06.001.

[10] E. Padhan, K. Sarangi, Recovery of $\mathrm{Nd}$ and Pr from NdFeB magnet leachates with bi-functional ionic liquids based on Aliquat 336 and Cyanex 272, Hydrometallurgy. 167 (2017) 134-140. 
doi:10.1016/j.hydromet.2016.11.008.

[11] S. Pavon, M. Kutucu, M.T. Coll, A. Fortuny, A.M. Sastre, Comparison of Cyanex 272 and Cyanex 572 on the separation of Neodymium from a Nd/Tb/Dy mixture by pertraction, J. Chem. Technol. Biotechnol. (2017). doi:10.1002/jctb.5458.

[12] Y. Baba, F. Kubota, N. Kamiya, M. Goto, Selective Recovery of Dysprosium and Neodymium Ions by a Supported Liquid Membrane Based on lonic Liquids, Solvent Extr. Res. Dev. Japan. 18 (2011) 193-198.

[13] S. Pavón, A. Fortuny, M.T. Coll, A.M. Sastre, Rare earths separation from fluorescent lamp wastes using ionic liquids as extractant agents, Waste Manag. 82 (2018) 241-248. doi:10.1016/j.wasman.2018.10.027.

[14] I. De Michelis, F. Ferella, E.F. Varelli, F. Vegliò, Treatment of exhaust fluorescent lamps to recover yttrium: Experimental and process analyses, Waste Manag. 31 (2011) 2559-2568. doi:10.1016/J.WASMAN.2011.07.004

[15] P. Ramakul, T. Supajaroon, T. Prapasawat, U. Pancharoen, A.W. Lothongkum, Synergistic separation of yttrium ions in lanthanide series from rare earths mixture via hollow fiber supported liquid membrane, J. Ind. Eng. Chem. 15 (2009) 224-228. doi:10.1016/j.jiec.2008.09.011.

[16] J.N. lyer, S.D. Pawar, The phosphine oxides Cyanex-921, Cyanex-923 and Cyanex-925 as extractants for $\mathrm{Pb}$ (II) from aqueous media, Indian J. Chem. Technol. 9 (2002) 251-255.

[17] N. Kumar, T. Vander, D. Banerjee, K. Binnemans, Non-aqueous solvent extraction of rareearth nitrates from ethylene glycol to $n$-dodecane by Cyanex 923, Sep. Purif. Technol. 174 (2017) 544-553. doi:10.1016/j.seppur.2016.10.039.

[18] CYTEC Industries Inc., CYANEX 572 Extractant. Technical Brochure, Canada, 2013.

[19] CYTEC Industries Inc., CYANEX 923 Extractant. Technical Brochure, (n.d.).

[20] S.R. Crouch, H.V. Malmstadt, A Mechanistic Investigation of Molybdenum Blue Method for Determination of Phosphate, Anal. Chem. 39 (1967) 1084-1089. doi:10.1021/ac60254a027.

[21] Analytica Chimica Acta, The molybdenum blue reaction for the determination of orthophosphate revisited: Opening the black box, Edward A. Nagul, lan D. McKelvie, Paul Worsfold, Spas D. Kolev,. 890 (2015) 60-82. doi:10.1016/j.aca.2015.07.030.The.

[22] A. Surucu, V. Eyupoglu, O. Tutkun, Synergistic extraction of cobalt and nickel ions by supported liquid membranes with a mixture of TIOA and TBP, Desalin. Water Treat. 53 (2015) 1246-1253. doi:10.1080/19443994.2013.855664.

[23] X.J. Yang, A.G. Fane, K. Soldenhoff, Comparison of Liquid Membrane Processes for Metal Separations : Permeability, Stability, and Selectivity, Ind. Eng. Chem. Res. 42 (2003) 392403. doi:10.1021/ie011044z.

[24] C.S. Gholap, S. Panja, P.S. Dhami, J.S. Yadav, S.K. Ghosh, Journal of Environmental Chemical Engineering Supported liquid membrane transport studies of $\mathrm{Pu}$ (IV) using OTDA , a novel diamide, J. Environ. Chem. Eng. 7 (2019) 102784. doi:10.1016/j.jece.2018.11.029.

[25] B. Mahanty, P.K. Mohapatra, A. Leoncini, J. Huskens, W. Verboom, Chemical Engineering Research and Design Pertraction of americium (III) through supported liquid membranes containing benzene-centered tripodal diglycolamides ( Bz-T-DGA ) as an extractant / carrier, Chem. Eng. Res. Des. 141 (2018) 84-92. doi:10.1016/j.cherd.2018.10.023.

[26] V.L. Brisson, W. Zhuang, L. Alvarez-Cohen, Bioleaching of Rare Earth Elements from Monazite Sand, Biotechnol. Bioeng. 113 (2016) 339-348. doi:10.1002/bit.25823.

[27] S.S. Behera, P.K. Parhi, Leaching kinetics study of neodymium from the scrap magnet using acetic acid, Sep. Purif. Technol. 160 (2016) 59-66. doi:10.1016/j.seppur.2016.01.014.

[28] A. Kumari, M.K. Sinha, S. Pramanik, S.K. Sahu, Recovery of rare earths from spent NdFeB magnets of wind turbine: Leaching and kinetic aspects, Waste Manag. 75 (2018) 486-498. doi:10.1016/j.wasman.2018.01.033.

[29] T. Lashen, M. Cheira, D. Zaki, E. Allam, S. Mohamed, Leaching and Recovery of Rare Earth Elements From Altered Alkaline Granite Rock From Nusab El-Balgum Area, South Western Desert, Egypt., Int. J. Adv. Res. 4 (2016) 787-801. doi:10.21474/IJAR01/1548.

[30] C. Tunsu, J.B. Lapp, C. Ekberg, T. Retegan, Selective separation of yttrium and europium using Cyanex 572 for applications in fluorescent lamp waste processing, Hydrometallurgy. 166 (2016) 98-106. doi:10.1016/j.hydromet.2016.10.012.

[31] C. Tunsu, M. Petranikova, M. Gergorić, C. Ekberg, T. Retegan, Reclaiming rare earth elements from end-of-life products: A review of the perspectives for urban mining using hydrometallurgical unit operations, Hydrometallurgy. 156 (2015) 239-258. doi:10.1016/j.hydromet.2015.06.007.

[32] I. Puigdomenech, MEDUSA software, (2013).

[33] J. Wang, X. Liu, J. Fu, M. Xie, G. Huang, H. Wang, Separation and Purification Technology acid (USTB-2) for rare earths extraction and separation from chloride media, Sep. Purif.

Technol. 209 (2019) 789-799. doi:10.1016/j.seppur.2018.09.020. 
[34] N. Swain, S. Mishra, A review on the recovery and separation of rare earths and transition metals from secondary resources, J. Clean. Prod. (2019). doi:10.1016/j.jclepro.2019.02.094.

[35] C. Tunsu, Y. Menard, D. Øistein, C. Ekberg, M. Petranikova, Recovery of critical materials from mine tailings : A comparative study of the solvent extraction of rare earths using acidic , solvating and mixed extractant systems, J. Clean. Prod. 218 (2019) 425-437. doi:10.1016/j.jclepro.2019.01.312.

[36] N.S. Rathore, A. Leopold, A.K. Pabby, A. Fortuny, M.T. Coll, A.M. Sastre, Extraction and permeation studies of $\mathrm{Cd}(\mathrm{II})$ in acidic and neutral chloride media using Cyanex 923 on supported liquid membrane, Hydrometallurgy. 96 (2009) 81-87. doi:10.1016/j.hydromet.2008.08.009. 